This is a self-archived - parallel published version of this article in the publication archive of the University of Vaasa. It might differ from the original.

\title{
Risk-taking of the European Banks in CEECs : The role of national culture and stake vs shareholder view.
}

\author{
Author(s): Sist, Federica; Kalmi, Panu \\ Title: Risk-taking of the European Banks in CEECs : The role of \\ national culture and stake vs shareholder view. \\ Year: $\quad 2017$ \\ Version: Accepted manuscript \\ Copyright (C) 2017 the authors | Palgrave Macmillan, Cham
}

\section{Please cite the original version:}

Sist, F., \& Kalmi, P., (2017). Risk-taking of the European Banks in CEECs : The role of national culture and stake vs shareholder view. In: Carretta, A., Fiordelisi, F., \& Schwizer, P. (eds.) Risk Culture in Banking. Palgrave Macmillan Studies in Banking and Financial Institutions (p. 241-257). Palgrave Macmillan, Cham. https://doi.org/10.1007/978-3-319-57592-6_11 


\title{
Chapter 10 \\ Risk-taking of European banks in CEECs: the role of national culture and stake vs shareholder view
}

\author{
Federica Sist and Panu Kalmi
}

\subsection{Introduction}

Since the time the Central and Eastern European countries (CEECs) opened their markets to accept foreign owners for banks, starting the processes of privatization and internationalization (through inflows), the European bank system evolved by considering new strategies, in relation to this openness, above other forces as competition, crises, regulation, innovation and so on.

In literature, it is not yet entirely clear why European banks decided go to CEECs. Explanations of this phenomenon can be found in excessive domestic competition (Andries, Capraru, 2012), clients support during the internationalization process, or simply presence in new countries to ride the wave of competitors. Anyway, the number of foreign owners in these countries has increased and studies on performance or efficiency demonstrate different results, though only the results on the importance of CEECs for the establishment of foreign branches, subsidiaries and strategic acquisitions in the banking and economic systems are shared in the literature. Starting from the interaction between the current literature on risk culture in banks and the strand of research on internationalization in the transition economy, where the issue of risk is more relevant than in other contexts, we develop a study focused on the influence of national culture on bank risk-taking. 
The national culture is measured by Hofstede (2001) by six dimensions: power distance, individualism, masculinity, uncertainty avoidance, long-term orientation and indulgence. Not all dimensions are used at the same time in the financial sector.

This study aims to understand the impact of national culture on risk-taking by European banks investing in CEECs. In addition, we inquire about the ownership effect (shareholders or stakeholder owned banks). In a further index we include concerns on the level of reform developed to account for country institution development in countries in transition. These elements and results contribute to the completion of the European context for the understanding of the banking system, revealing the internationalization behaviour of these types of financial institutions and giving the opportunity to make policy decisions or strategies concerning internationalization issues and bank regulations, especially for banking union goals and financial system integration. Our contribution to the literature serves as, to the best of our knowledge, the first study with an analysis of national culture and risk-taking of banks by ownership in CEECs, while other studies considered risk and internationalization from different points of view (Berger et al. 2015; Goetz et al. 2016; Ellul and Yeramilli, 2013;). Practitioners too will gain benefits from this work in their decision-making and planning strategies abroad.

This study elaborates the intersection of the studies on the relationship of national culture and risk-taking in corporations (Li et al. 2013, Mihet, 2013) and the studies on risktaking in banks (Bhagat et al. 2015; Buch and De Long, 2008). We regress risk-taking, the dependent variable, with two dimensions of national culture variables, the independent variables, to find if they affect risk in some direction. The control variables related to the banks and the country variables are necessary to evaluate the effectiveness of regression; two variables are about the countries, and the others give information on the bank itself. 
This study is outlined as follows: First, there is a literature review that begins to establish a relation between national culture and financial systems, continuing with the risk argument linked to internationalized banks or firms and dimensions used to measure national culture. Second, the session data, the methodology and variables are described. Finally, the results are explained and discussed, and conclusions are drawn.

\subsection{Literature review}

The dimensions of National Culture (NC) affect the financial system mechanisms in different ways. The preference toward banks rather than stock markets of a country depends on higher uncertainty-avoidance (Kwok, Tadesse 2006). Aggarwall and Goodell (2010) confirm and reinforce this result adding the inquiry of individualism and power distance, which imply a predilection for equity markets when their levels are high. Individualism is conducive to long-term financing of growing firms in market-based systems (Lee, Peterson 2000). Individualism is relevant for the firm growth in the presence of financial constraints; in fact, when individualism is high, the obstacles are overcome through the ability of the entrepreneur or manager in relation to the bank (Boubakri, Saffar 2016), while the power distance is negatively related with growth, as a complement to previous results. It is clear the NC affects the behaviour of operators and the approach of financing firms; it reflects an evident importance of the NC for operators as well as for banks and their risk, especially if the bank internationalises. The expansion in other markets requires the management of the differences between countries of origin and destination, as well as tailored strategies to arrange the business model and successful elements to survive the internationalization process: all these aspects make the risk evaluation of operations and financial services supply more complex. 
The geographic expansion of banks mitigates risk, not through the impact of loan quality, but by decreasing idiosyncratic local risk (Goetz et al. 2016, Akhigbe, Whyte 2003). Choi et al. (2010) find that the cross-border M\&As drive to a stabilization of earnings, even if Buch and De Long already in 2008 noted the reduction of risk in banks by acquiring foreign banks.

While the method of going abroad is an interesting topic, other relevant features can impact the risk of multinational banks, such as the distance of the country of destination from the country of origin and the levels of the dimensions of $\mathrm{NC}$ in the two countries.

CEECs are facing a change in their financial systems and banking structures, while the internationalization process has made an improvement in bank performance. The existing works in this context isolate different results between old and new Europe, likely according to the differences between these two areas. The liberalization process proceeds, and it is not taken for granted that the inflows will continue; in fact, the quality of market discipline can refuse foreign banks (Bertus et al. 2008).

In literature, national culture is used to evaluate the risk-seeking of firms, in fact, the behaviour of multinationals depends even upon the decisions made according to the cultural background of the employees within the firm. In banks too, decisions are affected by the national culture of the organization and managers (Carretta, Farina and Schwizer 2010); ownership is another important factor to understand the likelihood to prefer risky strategies (Mihet, 2013). The risk appetite should determine the choice of the country of destination since studies in this topic observe an impact of cultural characteristics in risktaking. Nonetheless, the Western European banks active in CEECs have an effectiveness culture of risk if they are efficient and not too risky during the time. $\mathrm{NC}$ is determinant in 
risk choices in going abroad first (way and destination) and in how supply services after. The observation of risk-taking allows us to understand if the risk culture of the Western European banks internationalized in those countries has encouraged more risk-taking, and if we find differences between the groups: Stakeholder Value (STV) and Shareholder Value (SHV).

The studies on risk culture in the banking system are few and they require going in deep on the cultural side because one of several variables can affect risk-taking in determining the riskiness of the bank itself. Even if the banks are treated as enterprises, we have to remember their particularly strategic double role of transferring financial flows and serving as an instrument for political economy. When they develop their own business, they cannot assume all of the risks as in entrepreneurship activity; this is the reason why risk-taking is a relevant topic. The escalation of consciousness of risk to reason as an enterprise, in this type of financial institution, implies constant attention to changes and evolution of regulation. In fact, from this view they take entrepreneurship risk above the typical risk of their own businesses. The internationalization process is a particularly risky activity, especially in transition economies, but in the current global world it is a necessary choice that has to be arranged coherently with the other strategies and its own model (Ferri et al. 2015). One issue that has been studied less often is the impact of the ownership structure of the parent bank on the behaviour of the daughter bank. Cooperative banks have been shown to take much less risk than profit-maximizing banks (Hesse, Cihak, 2007). However, it is not clear whether this finding extends to the daughter banks of cooperative groups. 
The individualism and power distance are the two dimensions of NC in which we are interested. The first is more commonly used as an independent variable in finance and it always returns significant results, the meaning varies on the aim of the author, so in Li et al. (2013) it predicts the rule of law, in Mihet (2013) it is the mirror of the decisions made by overconfidence and over-optimism (Ashraf et al. 2016). Instead, Boubakri and Saffar (2016) believe the ability to overcome financial constraints is approximated by individualism itself. If individualism is positively related with risk-taking, in previous studies, we must predict a movement in the same direction, but it is necessary to remember the banks analysed in this study are in a non-developed context with a banking structure not completely reformed, where results are not always aligned with other contexts.

HYP 1 Risk-taking of banks in CEECs increases if Individualism increases in the same geographic area.

Power distance is basic for the culture of risk; when this dimension is high, the decisions are made without an effective comparison between levels (Ashraf et al. 2016). The bottom-up process in assessing the environment is not applied because the communication channel is always vertical, but top-down (Boubakri and Saffar, 2016). The culture of risk in the Bank Holding Company (BHC) is imposed in an authoritarian manner and the subsidiaries and branches lose autonomy (regardless if they keep the BHC's model or not). Reasoning in a prudential way strictly compliant with procedure and without taking riskier decisions (Mihet 2013) restrains risk. This compliance with guidelines of the mother bank inhibits banks with high levels of power distance to take more risk. 
HYP 2 Risk-taking of banks in CEECs decreases if the Power distance increases in the same geographic area.

For European cooperatives can be affected from different features of the countries in which they operate (Fiordelisi, Mare 2014). The two models, SHV and STV, are compatible both with non-collectivism (Ferri, Leogrande 2015), so any ownership effect in terms of different models is awaited. If HYP3 is true, the risk culture of BHCs is indifferent in evaluating the risk-taking of their daughters in countries where reform of banking structure is not complete.

HYP 3 The banks that are owned by shareholders are related to risk-taking with the same sign of banks with stakeholders holding.

\subsection{Methodology}

The national culture is measured by Hofstede (2001) in six dimensions: power distance, individualism, masculinity, uncertainty avoidance, long-term orientation and indulgence. The scores assigned are in a range of 0 to 100 , and in our sample, the measure can vary from 20 to 80 for Individualism with a mean of 44, while power distance is from 40 to 100 and the mean is 73 ; therefore, CEECs are not very individualistic and have a strong presence of hierarchical mechanisms.

Risk-taking measures can express the overall risk taken through the volatility of bank earnings ( $\operatorname{Std}(\mathrm{ROA})$, with normalized ROA). In fact, a shared belief is that volatile earnings are the consequence of risky operations (John et al. 2008; Zhang, 2009) and the 
risk embodied in long-term investment results from $R \& D$ investments $(R \& D$ expenses to capitalization) ( $\mathrm{Li}$ et al. 2013). Mihet (2013) includes the z-score of each firm, and it is therefore interesting to evaluate the risk-taking of banks through z-scores (Ashraf et al. 2016; Bhagat et al. 2015; Berger et al. 2015; Mihet 2013) as well. Z_score is calculated as $\mathrm{Z}=(\mathrm{ROA}+\mathrm{CAR}) / \sigma(\mathrm{ROA})$, where ROA is earnings before taxes and loan loss provision divided by assets, CAR is the capital-asset ratio, and $\sigma(\mathrm{ROA})$ is the standard deviation of the ROA over the entire sample period. The $\mathrm{Z}$ statistic indicates the number of standard deviations that a firm's losses (negative profits) can increase to deplete equity, making the firm insolvent (De Nicolo`2000).

The other measures considered in banking are: distance to default and measures related to the stock market as bond yield spreads, volatility of bank stock returns and the variance of BHC's stock returns (Goetz et al. 2016, Choi et al. 2010; Buch and DeLong 2008); however, in this study we cannot use these types of variables.

The ownership measure is, as usual, a dummy to isolate the model of banks or the ownership of CEECs, thus we analyse: the banks owned by Western European BHCs, in turn grouped into STV and SHV to capture different results by models, and banks with Eastern European owners, in turn separated into the state-owned banks and branches and subsidiaries owned by private BHC formed CEECs. The crisis years are always isolated through the dummy: equal to 0 if until the year 2008 is excluded, 1 otherwise.

The data to measure the risk-taking are from Bankscope, and national culture data are from the website managed by Hofstede. The sample is composed of 328 Eastern European banks in 13 countries. Table 1 presents the summary of variables of banks 
considered in the model, while table 2 to table $2 . d$ show the variables explanatory of financial structure in CEECs, both by all banks and groups studied.

To evaluate the effects of culture on risk-taking through we use the unobservable individual effects, while ordinary least squares (OLS) or general linear models (GLS) are not applicable because of the characteristics of the data set, some authors overcome this argument through the hierarchical linear mixed model. When the variables to be checked are not several, there are other solutions to avoid collinearity. The data set is panel data, and the scores of national culture are time invariant as to years and they change country by country. The individuals (the banks) are not observable, so the problems of multicollinearity are solved through the Hausman-Taylor (1981) estimator for error-component models:

$$
y_{i t}=X_{1 i t} \beta_{1}+X_{2 i t} \beta_{2}+Z_{1 i} \delta_{1}+Z_{2 i} \delta_{2}+\mu_{i}+\varepsilon_{i t}
$$

We create four different vectors, grouping different types of variables present in the panel and the $\mu_{i}(\mathrm{mu})$ catches the error-in-time invariant variables and all those variables with problems of endogeneity.

$\mu_{i}$ is the unobserved, panel-level random effect that is assumed to have a zero mean and finite variance $\sigma_{\mu}^{2}$ and to be independently and identically distributed (i.i.d.) over the panels.

$\varepsilon_{i t}$ is the idiosyncratic error that is assumed to have a zero mean and finite variance $\sigma_{\mu}^{2}$ and to be i.i.d. over all of the observations in the data. $y_{i t}$ is the $z_{-}$score. 
The time-varying variables are assigned at two different vectors: $X_{1 i t}$ (GDP per capita) with exogeneity, uncorrelated with $\mu_{i}$, variables and $X_{2 i t}$ (size, EBRD score of banking sector liberalization: banre_intr, NIM) embodies the endogenous variables, likely correlated with $\mu_{i}$. Both $Z_{1 i}$ (Power distance) and $Z_{2 i}$ (NC_Indiv) contain the timeinvariant variables assumed to be exogenous in the first vector and endogenous in the second.

The firm-level control variables are connected through z-scores, so size is always in positive relation with the z-scores. If it is confirmed, it will reinforce the results linked to the hypotheses, as the movement of NIM that should be in the same direction of the dependent variable. The country-level control variables are two dimensions: GDP per capita, often used for these types of studies, and the level of progress of reforms in the banking sector, used for CEECs.

Table 1. Summary of variables used in the model

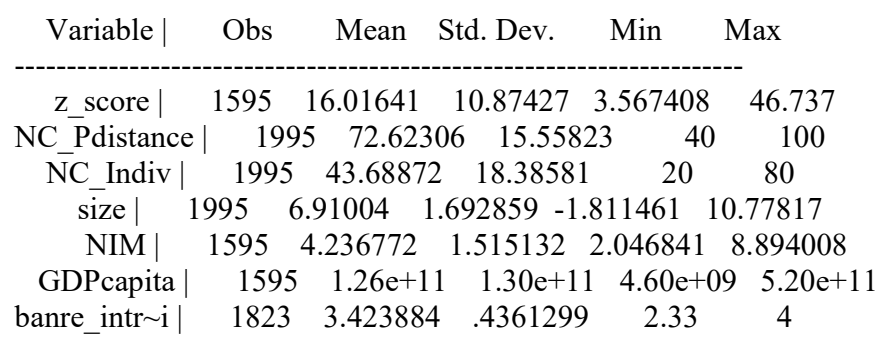

Note: See table 5 for variable descriptions

Table 2. Summary of key variables of the banking sector in CEECs

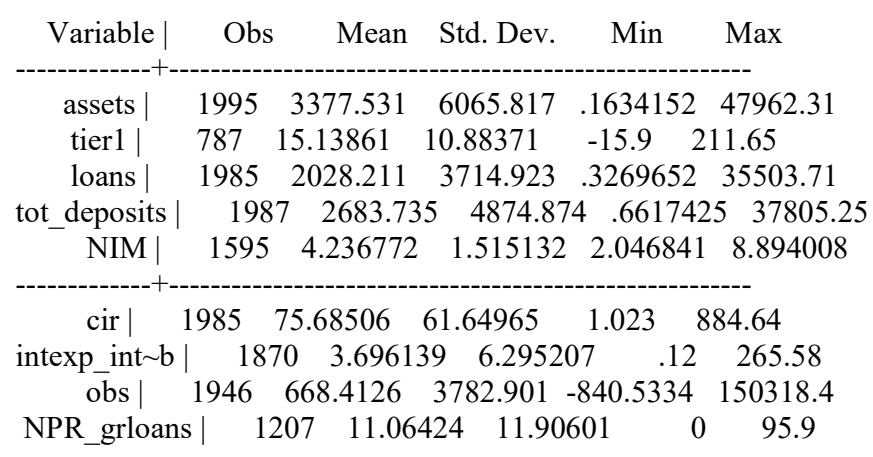


Table 2.a Summary of key variables of the banking sector in CEECs by WE SHVowned banks

$\begin{array}{ccccccc}\text { Variable } & \text { Obs } & \text { Mean } & \text { Std. Dev. } & \text { Min } & \text { Max } \\ - \text { assets | } & 802 & 4183.59 & 6601.572 & .1634152 & 38162.05 \\ \text { tier1 | } & 356 & 15.53166 & 8.108962 & -15.9 & 49.58 \\ \text { loans } \mid & 797 & 2546.199 & 3870.4 & .5008638 & 24401.61 \\ \text { tot_deposits | } & 796 & 3350.626 & 5353.323 & .6617425 & 30924.05 \\ \text { NIM } \mid & 660 & 4.262956 & 1.492512 & 2.046841 & 8.894008 \\ \text { cir } \mid & 797 & 71.79923 & 59.84503 & 1.023 & 884.64 \\ \text { intexp_int b | } & 755 & 3.855775 & 9.677528 & .12 & 265.58 \\ \text { obs | } 802 & 1036.34 & 5761.557 & -840.5334 & 150318.4 \\ \text { NPR_grloans | } & 506 & 9.72915 & 11.03826 & 0 & 95.9\end{array}$

Table 2.b Summary of key variables of the banking sector in CEECs by WE STVowned banks

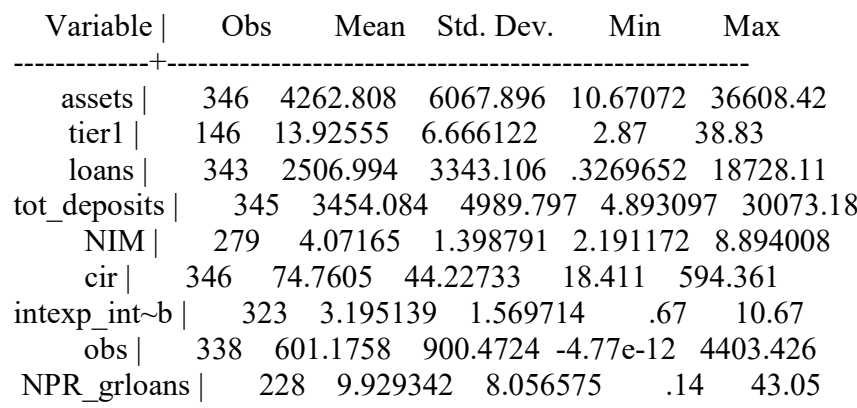

Table 2.c Summary of key variables of the banking sector in CEECs by State-owned banks

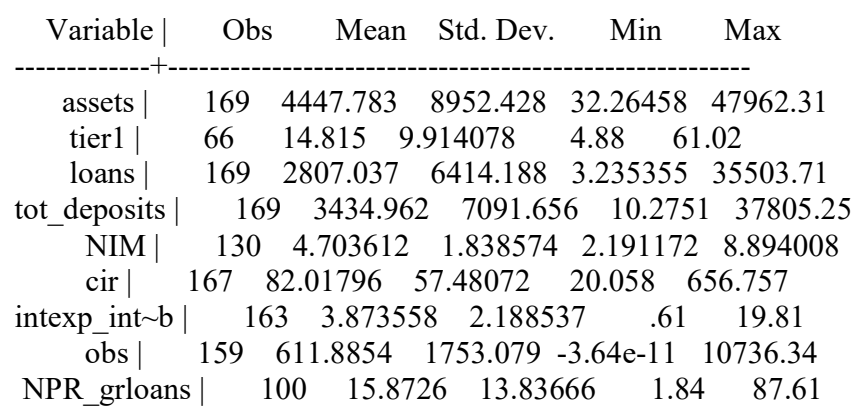

Table 2.d Summary of key variables of the banking sector in CEECs by EE-owned banks

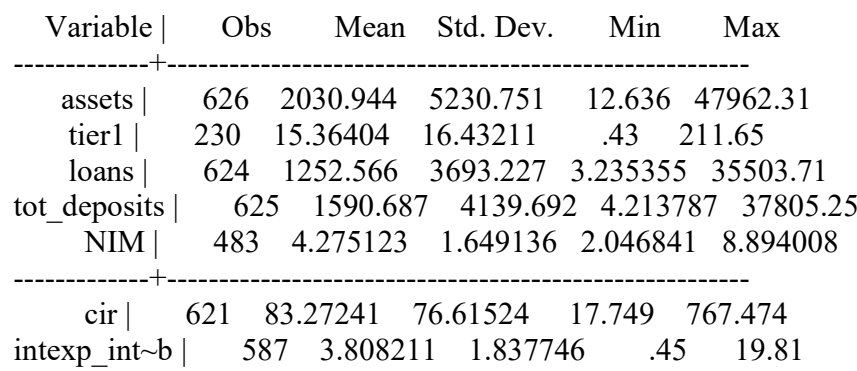


obs | $\quad \begin{array}{llllll}585 & 266.9828 & 965.2261 & -3.64 \mathrm{e}-11 & 10736.34\end{array}$ $\begin{array}{llllll}\text { NPR_grloans | } & 372 & 12.49046 & 12.37909 & 0 & 87.61\end{array}$ 


\subsection{Results}

The hypotheses about the relation between risk-taking and NC dimensions are significantly confirmed; when individualism and / or power distance increase, the z-score decreases, the HYP1 is confirmed. The NIM and size have a positive relation with the z-score; these variables are firm-specific control variables and the coefficients have a predictable sign because NIM is an item related to ROA, and we thus have a corroboration of the effectiveness of the estimation run. The coefficient of the variable on liberalization of the banking sector too has a rational sign; in fact, when the liberalization and privatization level of a country is increasing, the stability decreases at the beginning as a result of enhanced regulation (Table 3 ).

Table 3 shows, of course, that the crisis dummy moves in the same direction as the Z-score.

Table 3 Hausman-Taylor estimation with dummies

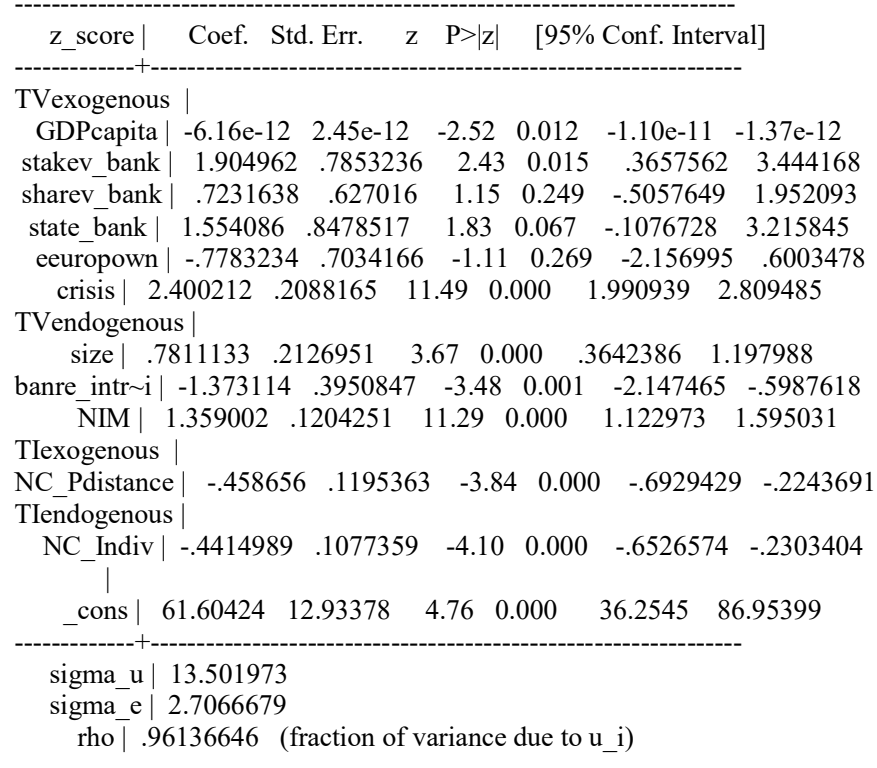

Note: TV refers to time varying; TI refers to time invariant.

Hausman-Taylor estimation: xthtaylor z_score \$xvars \$dummies, constant (NC_Pdistance NC_Indiv) endog(NC_Indiv size banre_intrali NIM) 
global xvars NC_Pdistance NC_Indiv size NIM GDPcapita banre_intrali; global dummies stakev_bank sharev_bank

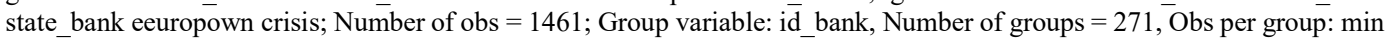
$=1, \overline{a v g}=5.4, \max =10$, Random effects u i $\sim$ i.i.d. Wald chi $2(10)=321.89$, Prob $>\operatorname{chi} 2=0.0000$ 
In particular, the stakeholders valued banks (cooperative and saving owned banks), and state owned banks are related to the z-score in a positive, statistically significant way. Banks of Eastern European holdings have shown negative signs even if it is nonstatistically significant. Thus, we can assert that the foreign owned banks are negatively related to risk-taking, especially if the holdings are cooperatives or savings.

In Table 4, the effect of crisis is investigated and any impact of crisis is indicated; the directions of relations are confirmed if compared with the previous results.

Table 4 Hausman-Taylor estimation by period of crisis

\begin{tabular}{|c|c|c|c|c|}
\hline \multirow{2}{*}{ Z_score } & \multicolumn{2}{|c|}{ Years $<2008 *$} & \multicolumn{2}{|c|}{ Years $\geq 2008^{* *}$} \\
\hline & Coeff & $\mathrm{P}>|\mathrm{z}|$ & Coeff & $\mathrm{P}>|\mathrm{z}|$ \\
\hline GDPcapita & $1.19 \mathrm{e}-11$ & 0.012 & $5.03 \mathrm{e}-12$ & 0.019 \\
\hline size & .8339045 & 0.005 & .2686516 & 0.192 \\
\hline banre_intr $\sim \mathrm{i}$ & -2.222979 & 0.000 & -1.601133 & 0.000 \\
\hline NIM & 1.014647 & 0.000 & .9858797 & 0.000 \\
\hline NC_Pdistance & -.5841814 & 0.000 & -.6330776 & 0.000 \\
\hline NC_Indiv & -.5806055 & 0.000 & -.6602032 & 0.000 \\
\hline \multicolumn{5}{|c|}{ 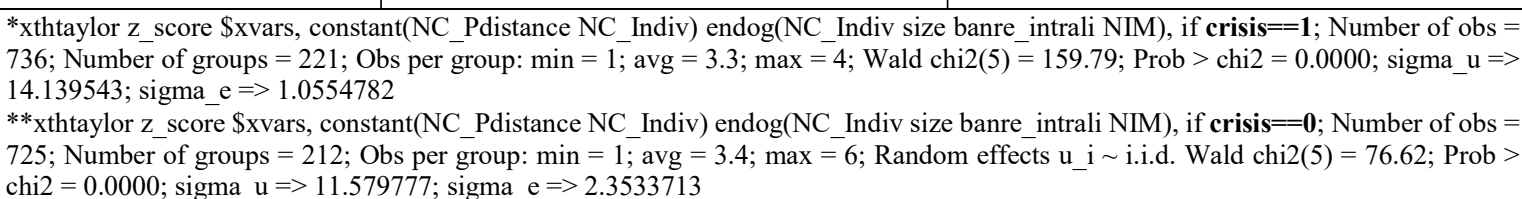 } \\
\hline
\end{tabular}


Table 5 Description of variables

\begin{tabular}{|c|c|}
\hline Variables & Description \\
\hline Z_score & $\begin{array}{l}\mathrm{Z}=(\mathrm{ROA}+\mathrm{CAR}) / \sigma(\mathrm{ROA}) \text {, where ROA is earnings before taxes and loan loss provision divided by assets, CAR } \\
\text { is the capital-asset ratio, and } \sigma(\mathrm{ROA}) \text { is the standard deviation of the ROA over the entire sample period. The } \mathrm{Z} \\
\text { statistic indicates the number of standard deviations that a firm's losses (negative profits) can increase to deplete } \\
\text { equity, making the firm insolvent (De Nicolo` 2000). }\end{array}$ \\
\hline GDPcapita & It compares GDP on a purchasing power parity basis divided by population as of 1 July for the same year. \\
\hline size & Ln(Total asset) \\
\hline NIM & Net interest margin $(\%)$ \\
\hline crisis & Dummy variable, 0 if year $<2008,1$ otherwise \\
\hline State_banks & dummy variable, owned by the state \\
\hline Sharev_bank & dummy variable, largest owner Western European shareholder bank \\
\hline Stakev_bank & dummy variable, largest owner Western European savings or a cooperative bank \\
\hline eeuropown & dummy variable, largest owner Eastern European bank \\
\hline banre_intr $\sim \mathrm{i}$ & $\begin{array}{l}\text { 1 Little progress beyond establishment of a two-tier system. } \\
2 \text { Significant liberalisation of interest rates and credit allocation; limited use of directed credit or interest rate } \\
\text { ceilings. } \\
3 \text { Substantial progress in establishment of bank solvency and of a framework for prudential supervision and } \\
\text { regulation; full interest rate liberalisation with little preferential access to cheap refinancing; significant lending to } \\
\text { private enterprises and significant presence of private banks. } \\
4 \text { Significant movement of banking laws and regulations towards BIS standards; well-functioning banking } \\
\text { competition and effective prudential supervision; significant term lending to private enterprises; substantial } \\
\text { financial deepening. } \\
4+\text { Standards and performance norms of advanced industrial economies: full convergence of banking laws and } \\
\text { regulations with BIS standards; provision of full set of competitive banking services. "+" and "-" ratings are treated } \\
\text { by adding } 0.33 \text { and subtracting } 0.33 \text { from the full value. Averages are obtained by rounding down, for example. a } \\
\text { score of } 2.6 \text { is treated as } 2+, \text { but a score of } 2.8 \text { is treated as 3-. }\end{array}$ \\
\hline NC_Pdistance & $\begin{array}{l}\text { The extent to which less powerful members of a society accept and expect that power is distributed unequally } \\
\text { (Hofstede 2001) }\end{array}$ \\
\hline NC_Indiv & $\begin{array}{l}\text { A society in which the ties between individuals are loose. Everyone is expected to look after himself and his } \\
\text { immediate family only. Collectivism stands for a society in which people from birth onwards are integrated into } \\
\text { strong, cohesive in-groups, which throughout people's lifetime continue to protect them in exchange for } \\
\text { unquestioning loyalty (Hofstede 2001) }\end{array}$ \\
\hline
\end{tabular}




\subsection{Conclusion}

Building a new body of literature about risk culture is necessary to achieve the analysis of the determinants of risk-taking. In intermediation activities, the national culture can explain the success of operations abroad, but financial and economic results too, where banks are strongly related to the risk taken. The issue of risk is fundamental in multinational banks and the country of destination features an impact on risk for the branch or subsidiary, especially in terms of culture.

Individualism and power distance affect significantly the risk-taking measured by z-score. The same direction of individualism and risk-taking can be explained by the probable presence of financial constraints, that implies a greater relation between people during the negotiation and the increase of the presence of relationships in banking. Low levels of collectivism imply absolutely more negotiation, bringing to a more argued granting of loans, but not necessary well informed of relative risk. The direct relation of the bank with a manager or entrepreneur should force the assignment of the loan independently of the actual project risk.

From the point of view of branches and subsidiaries, we find lower risk-taking if the power distance dimension is low. When the autonomy of daughter banks is lesser, as in the case of higher-level power distance, the procedures to assess the risk to be taken are less flexible, behaving at a lower level of risk or at least the risk required by BHC.

The control variables give reasonable signs, for example the positive relation of the EBRD index, that means the level of reform to liberalize, privatize and regulate the banking 
sector in CEECs increases, at least initially, inducing instability. This result suffers the limits of the measure we used as proxy of risk-taking. The coefficient of the size is positive as usual.

The results on SHV and STV suggest that banks with cooperative BHCs in CEECs have the same behaviour as commercial banks in facing cultural characteristics of a host country; it can likely be caused by the homogenous instability of CEECs submitted to constant reforms.

The results obtained by this study help regulators to consider the different models in daughters' banks operating globally and professionals to plan risk management and internationalization activities due to the analysis of $\mathrm{NC}$ in the country of destination. The contribution we make is to build the literature around the relevant topic of risk culture in banks, especially in terms of internationalization. 


\section{References}

Aggarwal, R. and Goodell, J. W. "Markets and institutions in financial intermediation: National characteristics as determinants." Journal of Banking and Finance 33(2009):1770-1780.

Akhigbe, A. and Whyte, A. M. "Changes in Market Assessment of Bank Risk Following the Riegle-Neal Act of 1994." Journal of Banking and Finance (2003)27: 87102.

Ayadi, R and De Groen, W. P. "Banking Business Models Monitor 2014 Europe." Brussels, Montréal: IOFSC \& CEPS (2014).

Andrieş, A., M. and Bogdan, Căprarua, B. "The nexus between competition and efficiency: The European banking industries experience." International business review (2014)23:566-579.

Ashraf, B., N. "Effects of national culture on bank risk-taking behavior." Research in International Business and Finance (2016)37: 309-326.

Baltagi, Badi H. A Companion to Econometric Analysis of Panel Data. Chichester, UK: Wiley (2019)in Econometric Analysis of Panel Data. 5th ed., ed Baltagi, Badi H., Chichester, UK: Wiley (2013). 
Berger, A. N., Ghoul, S.vE., Guedhami, O. and Roman, R. A. "Internationalization and bank risk.” Research working papers(2015)15-08.

Bertus, M., Jahera Jr., J. S. and Yost, K. 2008.“A note on foreign bank ownership and monitoring: an international comparison." Journal of Banking \& Finance 32(2008):338-345.

Bhagat, S., Bolton, B. and Lu, J. 2015."Size, Leverage, and Risk-Taking of Financial Institutions.” Journal of banking \& finance 59(2015):520-537.

Boubakri, N. and Saffar, W.. "Culture and externally financed firm growth." Journal of corporate finance 41(2016): 502-520.

Buch, C. M. and DeLong, G. 2008.“Do weak supervisory systems encourage bank risk-taking?” Journal of financial stability 4(2008):23-39.

Carretta, A., Farina, V. and Schwizer, P. 2010"The "day after" Basel 2: do regulators comply with banking culture?" Journal of Financial Regulation and Compliance 18(2010):316-332.

Choi, S., Francis and B. B., Hasan, I.. "Cross-Border Bank M\&As and Risk: Evidence from the Bond Market.” Journal of Money, Credit and Banking 42(2010):615645. 
De Nicolò, G. 2000. "Size, Charter Value and Risk in Banking: An International Perspective.” IFC Discussion Paper No. 689, Washington, D. C.: Board of Governors of the Federal Reserve.

Ellul, A. and Yerramilli, V. "Stronger Risk Controls, Lower Risk: Evidence from U.S. Bank Holding Companies.” The journal of finance 68(2013):1757-1803.

Elsas, R. "Empirical determinants of relationship lending." Journal of Financial Intermediation 14(2005):32-57.

Ferri, G., Kalmi, P. and Kerola, E. "Organizational Structure and Performance in European Banks: A Reassessment.” Advances in the Economic Analysis of Participatory \& Labor-Managed Firms 16 (2015):109-141.

Ferri, G, Leogrande, A. "Was the Crisis due to a shift from stakeholder to shareholder finance? Surveying the debate.” Euricse, Working Paper 76(2015).

Fiordelisi, F., Mare and D. S. 2014. “Competition and Financial Stability in European Cooperative Banks.” Journal of International Money and Finance 45(2014):116.

Goetz, M. R., Laeven, L. and Levine, R. "Does the geographic expansion of banks reduce risk?" Journal of Financial Economics 120(2016):346-362. 
Hausman, J. A. and Taylor, W. E. "Panel data and unobservable individual effects." Econometrica 49(1981):1377-1398.

Hesse, H. and Cihak, M.. Cooperative Banks and Financial Stability. IMF Working Paper 2(2007).

Hofstede, Gerard H. Culture's Consequences: Comparing Values, Behaviors, Institutions, and Organizations Across Nations. 2nd edition, Thousand Oaks, CA: Sage Publications (2001).

Kwok, C. and Tadesse, S. (2006), "National culture and financial systems." Journal of International Business Studies 37(2006):227-247.

Lee, S., M. and Peterson, S. J. "Culture, entrepreneurial orientation, and global competitiveness." Journal of World Business 35(2000):401-416.

Li, K., Griffin, D., Yue, H. and Zhao, L. 2013. "How does culture influence corporate risk-taking?" Journal of corporate finance 23(2013):1-22. 